\title{
"Education is the passport to the future": enabling today's medical teachers to prepare tomorrow's respiratory health practitioners
}

\author{
Sharon Mitchell'1 Konrad E. Bloch², Indre Butiene ${ }^{3}$, Brendan G. Cooper ${ }^{4}$, \\ Irene Steenbruggen ${ }^{5}$, Alanna Hare ${ }^{6}, K^{2}$ onstantinos Kostikas ${ }^{7}$, Ian M. Adcock ${ }^{8}$, \\ James Paton ${ }^{9}$, Monica Fletcher ${ }^{10}$, Robin Stevenson ${ }^{11}$, Gernot Rohde ${ }^{12}$ and \\ Anita K. Simonds ${ }^{13}$
}

\begin{abstract}
Affiliations: ${ }^{1}$ European Respiratory Society, Lausanne, Switzerland. ${ }^{2}$ Pulmonary Division, University Hospital Zurich, Zurich, Switzerland. ${ }^{3}$ Faculty of Health Science, Klaipeda University, Klaipeda, Lithuania. ${ }^{4}$ Lung Function and Sleep, University Hospitals Birmingham NHS Foundation Trust, Queen Elizabeth Hospital Birmingham, Birmingham, UK. ${ }^{5}$ Lung Function Laboratory, Isala Klinieken, Zwolle, The Netherlands. ${ }^{6}$ Sleep and Ventilation, Royal Brompton and Harefield NHS Foundation Trust, London, UK. ${ }^{7}$ 2nd Respiratory Medicine Department, University of Athens Medical School, Athens, Greece. ${ }^{8}$ Thoracic Medicine, National Heart and Lung Institute, Imperial College London, London, UK. ${ }^{9}$ Royal Hospital for Sick Children, School of Medicine, College of Medical, Veterinary, and Life Sciences University of Glasgow, Glasgow, UK. ${ }^{10}$ Chair of European Lung Foundation, Education for Health, Warwick, UK. ${ }^{11}$ Editor-in-Chief of the Journal of European CME. ${ }^{12}$ Department of Respiratory Medicine, Maastricht University Medical Centre, Maastricht, The Netherlands.

${ }^{13}$ Academic Department of Sleep and Breathing, Royal Brompton Hospital, London, UK.
\end{abstract}

Correspondence: Sharon Mitchell, 4 Avenue Ste-Luce, CH 1003 Lausanne, Switzerland.

E-mail: sharon.mitchelldersnet.org

@ERSpublications

ERS educational research seminar: bringing best practice in medical education to ERS educational programmes http://ow.ly/zdiBJ

"If we are to achieve results never before accomplished, we must expect to employ methods never before attempted"

Sir Francis Bacon 1561-1626.

British aviators Alcock and Brown made the first transatlantic flight in 1919 - In 2013, the total number of flights in Europe was 9.5 million.

In July 1969, Apollo 11 Commander Neil Armstrong landed on the moon - today you can book your flight to space online with Virgin Galactic.

Throughout the 1990s, medical education was transformed as a direct consequence of more complex patient needs and the reorganisation of healthcare delivery. Medical education refers to the educational process required to prepare the medical professional for entry into practice as well as provision of educational activities for lifelong learning. This educational process is aimed at physicians, nurses, technicians, physiotherapists, scientists and other related professions who deliver care to the patient and public. Today's medical professional is bound by demanding healthcare systems [1-3], internationalisation of localised diseases [4], shorter more intense training periods and dependence on medical technology [5].

Received: June 162014 | Accepted after revision: July 112014

Conflict of interest: Disclosures can be found alongside the online version of this article at erj.ersjournals.com. S. Mitchell is an employee of the European Respiratory Society. 
Global funds, trade and networks are all examples of initiatives that demonstrate our entry into an international, mobile era. In 1993, the European Council (EU) council directive 93/16 stipulated that those EU nationals holding an EU primary or specialist medical qualification were to be allowed to practice within any EU country [6]. We are aware that many European countries are heavily reliant on foreign-trained medical staff to support their medical systems [7]. Patient tourism has also warranted attention [8], as more and more patients opt to cross international borders in search of treatment.

The European Respiratory Society (ERS) International Congress welcomes respiratory health professionals from all over the world. As a provider of continuous medical education, ERS is responsible for provision of new forms of education to meet the needs of today's healthcare professionals. Strengthening education within ERS is no longer an option, but a priority for our society.

The ERS educational research seminar took place in Berlin, Germany, on May 9-10, 2014, bringing together key leaders of ERS education (Education Council, HERMES (Harmonised Education in Respiratory Medicine for European Specialists) task force chairs, junior members committee and patient representatives) with medical education experts from Canada, the Netherlands and the UK to present, debate and challenge the future plans for ERS education. In 2011, at the end of his mandate, Paolo Palange, chair of the ERS Education Council, initiated the ERS educational seminar to realise new possibilities for change within this important pillar of the society. Following this path to professionalise education within ERS, Anita Simonds, who now comes to the end of her remit as chair of the ERS Education Council, has taken the opportunity to look back at achievements, assess the current situation and set out future directions.

Key concepts on best practices in medical education were presented, including competency-based education, curriculum planning, design and implementation of programmes, competency basedassessments, simulation, developments in e-learning, multiprofessional collaboration and patient-related outcomes. The task for participants of the conference was to map the presented concepts to current ERS educational programmes.

\section{What are the educational requirements ERS must deliver to meet future healthcare needs?}

Medical education design has progressed from traditional teacher-centred didactic lectures to competencybased clinical workplace curricula [9] and opened the door to active learning and skills-based education. There has been much debate on the meaning and merit of competency-based education [10, 11], and differences between competence and performance in clinical practice [12]. From the literature it can be deduced that a competent healthcare practitioner has the ability to independently perform a professional task [13]. If postgraduate medical education is to transition to a competency-based framework, three broad objectives must be considered for action.

\section{1) Curriculum planning, design and delivery within a competency-based framework}

Before embarking on how curricula are designed and delivered for competency-based training and assessment, it is first useful to reflect on what we mean by a curriculum. The curriculum is more than a simple syllabus [14]. Rather it is a refined blend of educational strategies, course content, learning outcomes, educational experiences, assessments, educational environments, learning styles, personal timetables and programmes of work [15]. Medical schools have made a number of efforts to address political and societal changes in healthcare including evolution of curriculum planning and design. The Canadian Medical Education Directions for Specialists (CanMEDS) has provided a framework to catalogue the competencies essential to the medical expert. Similar efforts have been made by other institutions including the Accreditation Council for Graduate Medical Education (ACGME). To some extent, developments in research in this field have provided a platform for curricula planning and design with a specific focus on outcomes.

Delivery and implementation of competency-based curricula present further challenges to medical training institutions. In other words, how to bridge the gap between the written curricula and clinical practice! To operationalise the curricula the concept of Entrustable Professional Activities (EPAs) has been devised and implemented in the Netherlands. An EPA "can be identified as a unit to be entrusted to a trainee" $[9,13]$ and for practical purposes is a routine clinical activity based on speciality and sub-speciality considerations, such as being "on call" for acute admissions. To apply this model a matrix of professional activities and competencies is considered during the design phase. Individualised planning through the use of portfolios for each learner and taking into account variables of background, training and experience will incite the learner not only to attain but to apply knowledge, skills and attitudes within the clinical setting [13]. 


\section{2) Competency-based assessment of clinical skills}

In line with competency-based training, assessment of the medical practitioner has also merited educational reform. The traditional assessment tool of written examinations to evaluate knowledge is glaringly inadequate to assess ability within the clinical environment. The competency-based framework is subject to congruency across learning outcomes, assessment and educational activities [16], and so each of these elements must be considered to educate and prepare the medical professional for practice. Miller's model of clinical competence addresses the need to consider multiple assessment tools to complement the training programme (fig. 1) [17].

Broadening the scope of assessment roughly embraces two agents for change. Firstly, assessment must be used as a form of learning, providing guidance and support to address learning needs [18] and to empower the learner. Realising the value of effective and timely feedback in formative assessment is critical to the trainee's progression through the educational process. Feedback that is constructive and applicable to the learner supports reflection and leads to improvements in clinical skills [19, 20]. The use of multisource feedback both for trainees and trained specialists has been shown to improve behaviour [21].

Secondly, development of valid and reliable assessment tools are required to assess the top of Miller's pyramid (fig. 1) including work-based assessment [10]. Currently, within the portfolios of the various ERS educational programmes direct observation of procedural skills and learner self-directed assessment are being integrated as assessment tools for the HERMES initiative. For example, the acquisition of the competencies required to perform spirometry has been achieved by a blended and active approach to learning and assessment consisting of self-directed online learning and multiple choice question assessment, a portfolio of spirometry tests, and direct observation of procedural skills.

Implementing the curriculum: introduction of portfolios for training and assessment

During this reform of education, portfolios were introduced as a tool to evaluate a trainee's ability to perform in practice. Since their introduction into medical education in the early 1990's, the content and structure of the portfolio has related to a number of learning goals including assessment, learning and reflection and personal development $[22,23]$. What is evident from the literature is that the design of the portfolio must be fit for practice within a specific setting [24] and factors influencing the successful implementation of portfolios must be appreciated (fig. 2) [24]. With today's medical education model of competency-based training and assessment "implementation of the curriculum requires the use of portfolios" [9]. It is intended that ERS will develop an e-portfolio model that will best support the requirements of all ERS members. Crucially the e-portfolio will be designed to meet the needs of not only medical trainees, but also trained medical specialists working towards revalidation or recertification, and nurses, physiotherapists, scientists and technologists. This project will be guided by the ERS Medical Education Working Group, which met for the first time during this educational research seminar. This expert group will provide support to educational committees actively involved in producing educational guidelines and implementing educational strategies at a European and international level.

\section{3) Training of the medical teacher}

"Effectiveness of learning is enhanced when a mentor supports the portfolio process" [22]. Within the competency-based framework, education is no longer a teacher-driven approach as the learner is expected to share this responsibility. However, the medical teacher has assumed additional responsibilities involved in facilitating the learning cycle [4], delivery of reliable evaluations [25] and contribution to curriculum development [10]. The CanMeds model depicts the medical expert as a health advocate, a manager, a collaborator, a communicator, a professional and a scholar. With these responsibilities falling on the shoulders of our medical experts it has been assumed that educationalists must provide a structure for trained medical professionals to perform within each of these domains, with lifelong learning being necessary for lifelong practice. As a provider of continuous medical education, an obligation falls on ERS to meet the educational needs of trained specialists by providing a train-the-trainer model to educate the medical teacher in areas of skills-based training, learning styles and assessment.

Curriculum design, implementation, and assessment of clinical skills completed by the trained medical expert are essential components of competency-based education. With growing numbers of medical experts attending the ERS International Congress, we intend to meet the challenge of introducing new ways of providing active learning environments and skills-based training integrated into curricula for postgraduate trainees as well as trained respiratory medicine specialists. 


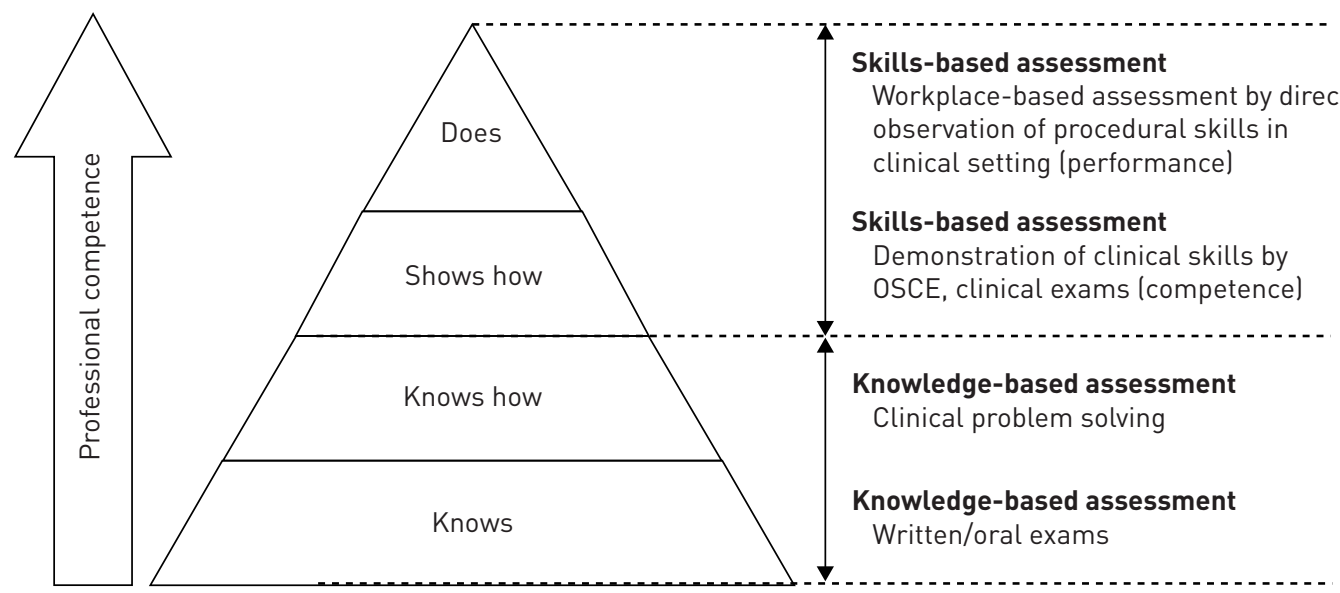

FIGURE 1 Miller's model of clinical competence. OSCE: objective structured clinical examinations. Reproduced from [17] with permission from the publisher.

\section{Given our entry into a mobile era, how can ERS ensure competence of medical professionals to offer high standards of patient care across borders?}

Fundamental to the delivery of consistent patient care are acceptable and applicable standards for education and practice across European borders. Following in the footsteps of the Bologna agreement in 1999, the Tuning project (Medicine) was launched with the specific goal of regulating learning outcomes/ competences for undergraduate medical education to degree level [26]. At national level we are aware that changes are also taking place within postgraduate medical specialist training and certification [6]. Unfortunately, this has not gained momentum at a European level for all specialities, as this task has fallen on the various European societies to produce consensus standards for postgraduate education for the medical specialties. The European Society of Cardiology, European Board of Urology and European Society of Anaesthesiology have all taken up this opportunity and likewise ERS has produced standards and frameworks for medical training institutions to join or opt into.

Trends within the healthcare system have highlighted the need for standards in order to demonstrate the quality of medical education that should be aspired to [1]. In keeping with areas defined by the World Federation for Medical Education [1], the HERMES initiative draws on the various mechanisms for teaching and learning for both trainees and trained specialists within various subspecialty areas of respiratory medicine (fig. 3). Figure 3 illustrates the HERMES processes from curriculum development through to the creation of standards and frameworks required to successfully implement educational programmes, educational resources, assessments, continuing medical education and accreditation for training centre networks. More information may be found on the HERMES website (hermes.ersnet.org).

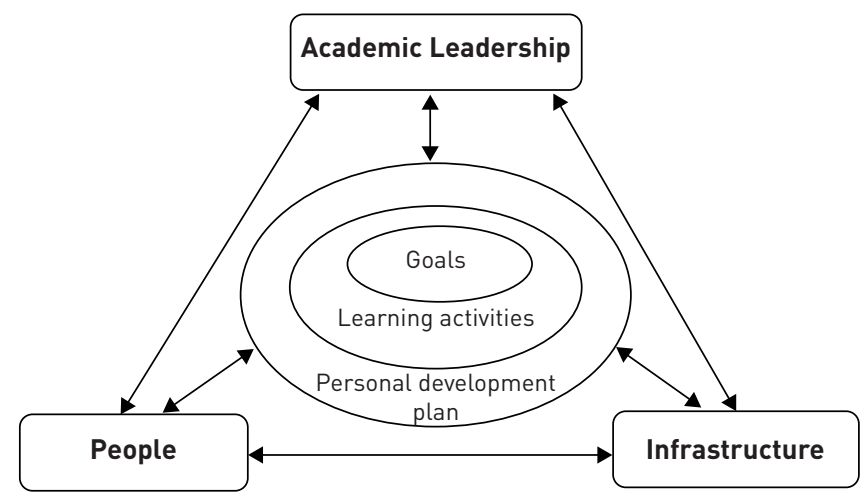

FIGURE 2 Model of the factors influencing successful introduction of portfolios in medical education. Reproduced from [24] with permission from the publisher. 


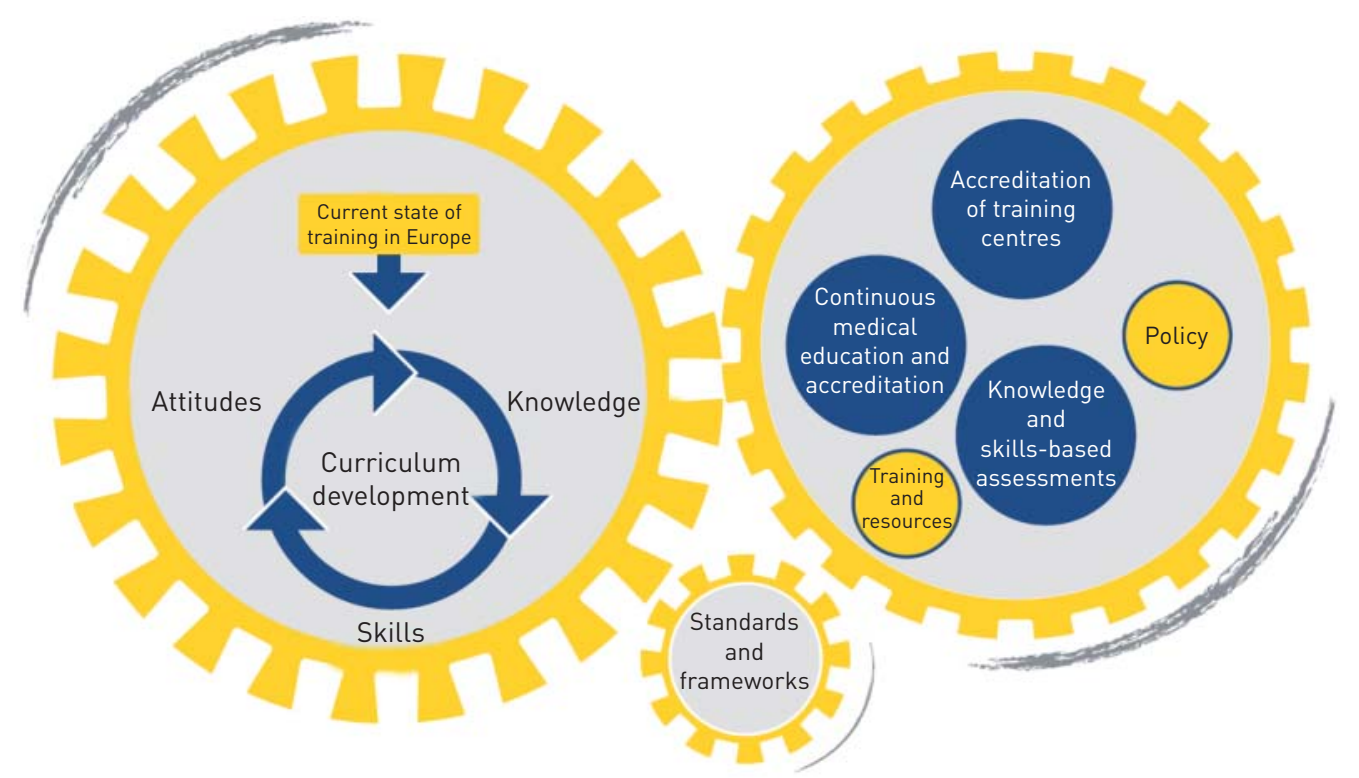

FIGURE 3 HERMES (Harmonised Education in Respiratory Medicine for European Specialists) processes from curriculum development through to the creation of standards and frameworks required to successfully implement educational programmes.

\section{Influences of healthcare system reform}

To achieve sound educational design, HERMES task forces are required to acknowledge the profound change in healthcare delivery. The re-allocation of traditional responsibilities within the healthcare team is well-recognised given the evolution of healthcare systems. Consequently, the focus has shifted to the design of educational programmes that cover the requirements of allied health professionals, medical specialists, physician assistants and scientists in order to deliver competencies to fulfil specific tasks [27]. The challenge for the HERMES initiative is to strike a balance between expected outcomes for the allied health professional and what the allied health professional is legally permitted to perform within individual countries. Further consideration must also be given to an increased focus on the treatment and diagnosis of disease across specialties. This reality leads to the possibility of team-based learning in delivery of the curricula. Each of the HERMES projects has been adapted to ensure influences on learning and practice are integrated into the planning phase.

\section{Information technology and online publications}

With a focus on learner-centred education, never before has information technology been more central to the education cycle of the medical professional. As a European society with members located around the world, how better to deliver standardised educational programmes than use of online learning within a blended learning approach? In the past 10 years, the impact of electronic learning has featured in abundance within the literature [28, 29]. Mobile learning has ensured that we now have access to up-to-date information as needed. Within ERS, developments of e-learning technologies have included podcasts, continuing medical education tests, procedure videos, webcasts, case reports and skills-based simulator training in noninvasive ventilation, all of which are available on the ERS educational resources website. The challenge for e-learning within ERS will be to carefully integrate e-learning into existing medical curricula. We have mentioned the development of an e-portfolio, but other future activities will be development of additional simulators, mobile learning (for smartphones and tablets), provision of online networking opportunities, and games as tools to support learning. Educating trainees, trained specialists and allied health professionals online will require use of both synchronous resources, using real-time exchange of information and live online courses, and also asynchronous resources, whereby students have the opportunity to complete a training course at their own pace and according to their personal schedule.

The ERS journals have also increasingly become digital entities, with a continuously developing online presence. Most recently, Breathe, the society's educational, practice-focused journal, launched a new open access website. As user needs continue to evolve, ERS will investigate new and innovative ways of presenting information online. 
How are patient needs considered in shaping medical education within ERS? As William Osler (1848-1919) said: "Listen to your patient, he is telling you the diagnosis".

Well-educated and well-informed patients have contributed to the changing paradigm in medical education. Patient and public involvement is gaining momentum across Europe and recognition at EU level, for example the World Health Organization First European Conference on Patient Empowerment Living with Chronic Disease was held in 2012. If improving patient care is the intended end goal of implementing best practices in medical education, it seems logical that patients also contribute to the quality measures. In collaboration with the European Lung Foundation, the ERS Education Council is exploring new ways to involve patients in the design and implementation of educational programmes.

\section{What else did we learn at the educational research seminar?}

Nearly all respiratory practitioners work in teams. Caroline Pelletier (Institute of Education, University of London, London, UK), a specialist in medical simulation and digital gaming described the relationship between "representation" and clinical practice, and how technology can shape how we view medical conditions during simulated scenarios for medical or surgical teams, such as a cardiac arrest, or acute trauma management.

With the experts we discussed the thorny issue of giving truthful, constructive feedback to the poorly performing practitioner. As Jason Frank (Office of Specialty Education, Royal College of Physicians and Surgeons of Canada) explained, "be honest and precise - you are evaluating the competency in performing the task, not the person". A further area of fruitful collaboration was a debate on meeting the educational needs of all scientists, and reciprocally providing updates in basic science for clinicians. Progress in this area will further cement the cross-cutting links between science and education within the new ERS strategy.

\section{Conclusion}

Enhanced public and patient expectations of healthcare, as well as entry into a mobile era for both patients and medical practitioners, have motivated medical education providers to adapt, and prepare medical professionals more realistically for entry into practice. The delivery of medical education is now operating within a competency-based framework and medical schools have responded through transformation of curricula and assessment design and delivery. Trained specialists and allied health professionals have also been directly touched by increased complexity in diseases and comorbidities, a breakdown of traditional roles and multidisciplinary medicine. This transformation makes it essential that medical societies and providers of continuing medical education respond by implementing suitable educational strategies for reform. ERS, through the ERS Education Council, has embarked on a range of such measures for trainees, trained specialists and allied health professionals. Innovations in e-learning, blended learning approaches, development of simulators, e-portfolio implementation, updated curriculum design and delivery, and the introduction of skills-based assessments will all simultaneously contribute to the intended outcome. Our aim is to enable the respiratory medical professional to deliver high-quality healthcare to patients, wherever they may go!

\section{Acknowledgements}

The following faculty members contributed to the 2nd European Respiratory Society educational research seminar by presenting key concepts in medical education and facilitating discussions: I.M. Adcock, M. Balzan, K.E. Bloch, E. Boshuizen, J. Busari, I. Butiene, B.G. Cooper, M. Fletcher, J. Frank, K. Kostikas, R. Loddenkemper, J. Paton, C. Pelletier, E.L. Reeves, G. Rohde, D. Sokol, A.K. Simonds, I. Steenbruggen, R. Stevenson, P. Towning.

Participants in the educational research seminar took part in discussions and shared their experiences in medical education: I.M. Adcock, N. Ambrosino, A. Bjerg, K.E. Bloch, E. Boshuizen, J. Busari, I. Butiene, B.G. Cooper, E. Eber, M. Elliott, A. Farr, M. Fletcher, J. Frank, M. Gappa, G. Hardavella, A. Hare, I. Horváth, T. Jacinto, K. Kostikas, P. Kurosinski, R. Loddenkemper, A. Mathioudakis, F. Midulla, S. Mitchell, S. Nava, S. Orfanos, K. Ortrud, C. Pannetier, J. Paton, C. Pelletier, E.L. Reeves, G. Rohde, P. Schnabel, D. Sokol, A.K. Simonds, S. Skoczynski, I. Steenbruggen, R. Stevenson, D. Sokol, P. Towning, R. Zinsky.

Although he was unable to attend the seminar this year, Paolo Palange, as the past chair of ERS Education, has contributed greatly towards professionalising medical education within ERS.

\footnotetext{
References

Lilley P, Harden R. Standards and medical education. Med Teach 2003; 25: 349-351.

Leinster S. Medical education and the changing face of healthcare delivery. Med Teach 2002; 24: 13-15.

Manning PR, De Bakey L. Continuing medical education: the paradigm is changing. J Contin Educ Health Prof 2001; 21: 46-54.

Gukas I. Global paradigm shift in medical education: issues of concern for Africa. Med Teach 2007; 29: 887-892. Schwarz MR. Globalization and medical education. Med Teach 2001; 23: 533-534.

Lewington K. Changes to medical education over the past 20 years. Student BMJ 2012; 20: e3504.
} 
Wismar M, Glinos IA, Maier CB, et al. Health professional mobility and health systems. Evidence from 17 European countries. Euro Observer 2011; 13: 1-4.

8 Ramírez de Arellano AB. Patients without borders: the emergence of medical tourism. Int J Health Serv 2007; 37: 193-198.

9 Mulder H, Ten Cate O, Daalder R, et al. Building a competency-based workplace curriculum around entrustable professional activities: the case of physician assistant training. Med Teach 2010; 32: e453-e459.

10 Iobst WF, Sherbino J, Cate OT, et al. Competency-based medical education in postgraduate medical education. Med Teach 2010; 32: 651-656.

11 Glass JM. Competency based training is a framework for incompetence. BMJ 2014; 348: g2909.

12 Khan K, Ramachandran S. Conceptual framework for performance assessment: competency, competence and performance in the context of assessments in healthcare - deciphering the terminology. Med Teach 2012; 34: 920-928.

13 Ten Cate O, Snell L, Carraccio C. Medical competence: the interplay between individual ability and the health care environment. Med Teach 2010; 32: 669-675.

14 Prideaux D. ABC of learning and teaching in medicine: curriculum design. BMJ 2003; 326: 268-270.

15 Harden RM. AMEE Guide No. 21: Curriculum mapping: a tool for transparent and authentic teaching and learning. Med Teach 2001; 23: 123-137.

16 Biggs J, Tang C. Teaching for Quality Learning at University: What the Student Does. 3rd Edn. Maidenhead, Society for Research into Higher Education/Open University Press, 2007.

17 Miller GE. The assessment of clinical skills/competence/performance. Acad Med 1990; 65: Suppl., S63-S67.

18 Epstein RM, Hundert EM. Defining and assessing professional competence. JAMA 2002; 287: $226-235$.

19 Hill F. Feedback to enhance student learning: facilitating interactive feedback on clinical skills. Int J Clin Skills 2007; 1: 21-24.

20 Hauer K, Kogan J. Realising the potential value of feedback. Med Educ 2012; 46: 140-142.

21 Shrank WH, Reed VA, Jernstedt GC. Fostering professionalism in medical education: a call for improved assessment and meaningful incentives. J Gen Intern Med 2004; 19: 887-892.

22 van Tartwijk J, Driessen EW. Portfolios for assessment and learning: AMEE Guide no. 45. Med Teach 2009; 31: 790-801.

23 Driessen EW, van Tartwijk J, van der Vleuten C, et al. Portfolios in medical education: why do they meet with mixed success? A systematic review. Med Educ 2007; 41: 1224-1233.

24 van Tartwijk J, Driessen EW, van der Vleuten C, et al. Factors influencing the successful introduction of portfolios. Qual Higher Educ 2007; 13: 69-79.

25 Kogan JR, Conforti L, Bernabeo E, et al. Opening the black box of clinical skills assessment via observation: a conceptual model. Med Educ 2011; 45: 1048-1060.

26 Cumming A, Ross M. The Tuning Project for Medicine - learning outcomes for undergraduate medical education in Europe. Med Teach 2007; 29: 636-641.

27 Eitel F, Kanz KG, Tesche A. Training and certification of teachers and trainers: the professionalization of medical education. Med Teach 2000; 22: 517-526.

28 Ruiz JG, Mintzer MJ, Leipzig RM. The impact of e-learning in medical education. Acad Med 2006; 81: $207-212$. Masic I. E-Learning as new method of medical education. Acta Inform Med 2008; 16: 102-117. 